\title{
Comparative Effectiveness of Hierarchical, Flowchart and Spider Concept Mapping Strategies on Students' Performance in Chemistry
}

\author{
Bamidele, E.F., ${ }^{1, *} \&$ Oloyede, E. O. ${ }^{1}$ \\ ${ }^{1}$ Department of Special Education and Curriculum Studies, Faculty of Education, Obafemi Awolowo University, \\ Ile-Ife, Nigeria \\ *Correspondence: Department of Special Education and Curriculum Studies, Faculty of Education, Obafemi \\ Awolowo University, Ile-Ife, Nigeria E-mail: bamdeleef@yahoo.com
}

Received: July 27, 2012 Accepted: August 5, $2012 \quad$ Online Published: February 16, 2013

doi:10.5430/wje.v3n1p66 URL: http://dx.doi.org/10.5430/wje.v3n1p66

\begin{abstract}
This study investigated the relative effectiveness of three types of concept maps (hierarchy, flowchart and spider) on the performance of students in Chemistry. This is with a view to find out which of the concept mapping types is more superior in enhancing students' performance in the numerical aspect of Chemistry. The pre-test, post-test experimental design was used for the study. The population for the study comprised of all the Chemistry students in Senior Secondary School in Osun State of Nigeria. Students in Senior Secondary class two (SSII) in their intact classes from three schools in Ife-Central local government area of the state formed the sample of the study. The three schools were randomly assigned to the hierarchical, flowchart and spider concept mapping strategies. The instrument used for data collection was the Problem Solving Achievement Test in Chemistry (PSATC). Students in the three groups were taught using the three kinds of concept maps separately. The experiment lasted for five weeks after which a post-test was administered. The result of the study indicated that there was no significant difference in the performances of the students in the three groups with respect to the kind of concept map used. ( $F=1.088 ; p>0.05)$. This implies that the concept mapping strategies were not all that different in their superiority. They all produced a similar effect on the students with respect to their performance in Chemistry. However, it was found out that they enhanced the performance of students in their problem solving skills in Chemistry as already reported by research studies.
\end{abstract}

Keywords: concept maps; hierarchical; spider; flowchart; problem-solving; strategies

\section{Introduction}

Chemistry is one of the core science subjects in the secondary school curriculum which is relevant for agricultural, industrial and technological development of a nation. The National Policy on Education in Nigeria (N.P.E. 2004, section 5(2.2)) states in specific term that, secondary education shall provide technical knowledge and vocational skills necessary for agricultural, industrial, commercial and economic development. Since the knowledge of chemistry is central to vocations in health services, pharmaceuticals, petroleum and petrochemical industries, agriculture, food processing, teaching services and extractive industries, relevant for agricultural, industrial and economic development, then the teaching of Chemistry should aim at developing in the students those manipulative and experimental skills necessary to make him/her to be competent and confident in the investigations of the material resources around him/her so as to enable them acquire the required knowledge relevant for industrial and technological advancement of the nation.

However, as important as this subject is to all science related vocations, the performance of students in it at the Senior School Certificate level is a matter that requires prompt intervention. Students performed below average in external examinations like West African Senior School Certificate Examination (WASSCE) and National Examination Council (NECO). Evidence for this can be observed in the Chemistry results of students in Senior School Certificate Examinations (WAEC) from 2003 to 2010 in Table 1 below. 
Table 1: Trends of Performance in Chemistry in the West African Senior School Certificate Examination May/June 2003-2010

\begin{tabular}{lllllll}
\hline YEAR & TOTAL & TOTAL & TOTAL & \multicolumn{2}{l}{ NUMBER AND PERCENTAGE } \\
& ENTRY & EXAMINED & ABSENT & \multicolumn{2}{l}{ WITH GRADES } & \\
\cline { 5 - 7 } & & & & CREDIT & PASS & FAIL \\
& & & & $1-6$ & $7 \& 8$ & 9 \\
\hline 2003 & \multirow{2}{*}{412480} & 405447 & 7033 & 165513 & 92909 & 84875 \\
& & $(98.29 \%)$ & $(1.70 \%)$ & $(40.82 \%)$ & $(22.91 \%)$ & $(20.93 \%)$ \\
2004 & 340367 & 333272 & 7095 & 124250 & 84384 & 111188 \\
& & $(97.91 \%)$ & $(2.08 \%)$ & $(37.28 \%)$ & $(25.31 \%)$ & $(33.36 \%)$ \\
2005 & 361575 & 353656 & 7919 & 179156 & 65804 & 96537 \\
& & $(97.80 \%)$ & $(2.19 \%)$ & $(50.65 \%)$ & $(18.63 \%)$ & $(27.28 \%)$ \\
2006 & 393207 & 383694 & 9513 & 173103 & 87645 & 116230 \\
& & $(97.58 \%)$ & $(2.41 \%)$ & $(45.11 \%)$ & $(22.84 \%)$ & $(30.29 \%)$ \\
2007 & 434460 & 424741 & 9719 & 196081 & 105602 & 112637 \\
& & $(97.76 \%)$ & $(2.23 \%)$ & $(46.16 \%)$ & $(24.86 \%)$ & $(26.51 \%)$ \\
2008 & 468291 & 456993 & 11298 & 198621 & 121139 & 116892 \\
& & $(97.58 \%)$ & $(2.41 \%)$ & $(43.46 \%)$ & $(26.50 \%)$ & $(25.57 \%)$ \\
2009 & \multirow{2}{*}{478235} & 468546 & 9689 & 204725 & 114697 & 110260 \\
& & $(97.97 \%)$ & $(2.03 \%$ & $(43.69 \%)$ & $(23.41 \%)$ & $(25.39 \%)$ \\
2010 & 568291 & 565643 & 11930 & 236059 & 109944 & 98165 \\
& & $(97.50 \%)$ & $(2.50 \%)$ & $(50.70 \%)$ & $(23.61 \%)$ & $(26.08 \%)$ \\
\hline
\end{tabular}

Source: West African Examination Council, Nigeria

It could be observed from the table that students with grade A1 to C6 were always below $50 \%$. It then implies that these few numbers of students had the opportunity of securing admission into science related courses like medicine, agriculture, pharmacy, geology, physical sciences, science education and technology in the higher institutions.

The poor performance has been traced to several factors which may include the methods of teaching employed by the teachers which is not in line with the modern methods that involves the use of information technology and some other novel and interesting methods that can make the students to learn the subject meaningfully. Etiubon (2007) identified teaching resources and its manipulative adaptations as a factor. Similarly, Ezeliora (1999) and Eniayeju (2005) also pointed out that the use of concrete materials facilitates better and proper understanding of chemistry concepts. Salau (2003) and Njoku (2004) identified students' attitude towards learning as a factor.

Presently, in Nigerian secondary schools, many of the chemistry teachers adhere strictly to the teacher expository method of teaching. This might be partly due to their desire to cover the syllabus and partly to their attitude towards teaching due to the poor economic situation in the country that does not encourage the average Nigerian teacher in trying out new methods of teaching because of the perceived costs of the teaching materials. This has led to teachers not exposing the students to meaningful learning, and this at the same time has made students to perceive Chemistry as abstract and a very difficult subject to understand.

One aspect of the subject that students have been finding difficult is the mole concept which cut across all aspects of Chemistry. The chief examiner reports of West African School Certificate Examination have consistently asserts that students are deficient in the use of mole concept which is the bedrock of stoichiometry in chemistry. Stoichiometry is the branch of Chemistry and chemical engineering that deals with the quantities of substances that enter into, and are produced by chemical reactions. Every chemical reaction has its characteristic proportions. The method of obtaining these from chemical formulae, equations, atomic weights, and molecular weights, and determination of what and how much is used and produced in chemical processes is the major concern of stoichiometry. Stoichiometry is viewed as the accounting, or mathematics behind chemistry. (Wikipedia, 2010).

However, Concept mapping has received much attention from science education researchers and it has been shown to 
be a useful tool to facilitate meaningful learning in science. For instance, concept mapping has been shown to improve problem-solving abilities (Pankratius, 1990); to reduce students' anxiety towards learning (Jegede, Alaiyemola and Okebukola, 1990); and to enhance achievement(Novak and Gowin 1984: Fisher, Faletti, Patterson, Thornton, Lipson and Spring, 1990; White and Gunstone, 1992; Tobin, Tippings and Gallard, 1994). Canas, Hill, Carff, Suri, Lott, Gomez, Eskridge, Arroyo, and Carvajal, (2004) and many more.

Concept maps are two or three-dimensional spatial or graphic displays that make use of labelled nodes to represent relationships between pairs of concepts. It has been suggested that the concept map structure parallels the human cognitive structure, as it shows how learners organize concepts (Fisher et al., 1990; Clarke, 1991; and Ferry et al, 1998). When concepts and linking words are carefully chosen, these maps can be useful classroom tools for observing nuances of meaning, helping students organize their thinking, and summarizing subjects of study (Canas, Hill, Granados \& Perez, 2003). From an educational perspective, a growing body of research indicates that the use of concept maps can facilitate meaningful learning (Coffey, Canas, Reicharzer, Hill, Suri and Carft, 2003) and performance support systems (Canas et al, 2003).Novak and Canas (2008) maintained that one of the reasons concept mapping is so powerful for the facilitation of meaningful learning is that it serves as a kind of template or scaffold to help to organize knowledge and to structure it, even though the structure must be built up piece by piece with small units of interacting concept and propositional frameworks. They observed that many learners and teachers are surprised to see how this simple tool facilitates meaningful learning and the creation of powerful knowledge frameworks that not only permit utilization of the knowledge in new contexts, but also the retention of the knowledge for long periods of time (Novak \& Canas, 2008). Research studies have indicated that there are different kinds of concept maps (hierarchical, flowchart, spider, system, landscape, mandalla-mandallae.t.c) and all have been found to facilitate meaningful learning and improve students' achievement in various school subjects.

Considering the results of research findings in favour of concept mapping and the fact that there are a variety of concept maps (http://classes.aces.uiuc.edu), this study intends to compare the relative effectiveness of using hierarchical, flowchart and spider concept-mapping strategies in teaching topics relating to the concept of mole.

\section{Objectives of the Study}

The objectives of this study are to:

1) Compare the relative effectiveness of three concept mapping strategies (hierarchical, flowchart and spider) on the performance of students in Chemistry; and

2) Determine which of the concept mapping strategies can best improve the numerical problem solving skills of students in Chemistry.

\section{Study Design and Sample}

The research study adopted a pre-test, post-test quasi-experimental design in which three public senior secondary schools were randomly selected in Ife Central Local Government Area of Osun State, Nigeria. Intact class of Chemistry students in Senior Secondary Class two (SSII) were selected for the study. A total of one hundred and fifty six (156) students formed the sample for the study. The age range of the students was between 13 and 17 years.Selected sample were randomly assigned to the treatment groups. The treatment involves the use of concept mapping strategies (Spider, Flowchart and Hierarchy) to teach the mole concept and related concepts that are associated with stoichiometry in Chemistry. A pre-test was used to determine the entry level of the subjects. The treatment was then carried out for five weeks after which a post-test followed to determine the effects of the treatments.

\section{Variables}

The variables examined in this study are:

1) Independent Variables: These are the learning strategies used in the study. They are

i. Hierarchical concept mapping;

ii. Flowchart concept mapping; and

iii. Spider concept mapping; 
2) Dependent variable: This is the Chemistry achievement test scores.

3) Intervening Variables: These are sex, study habit and academic achievement.

\section{Content Area for the Study}

The content in this study was based on the mole concept. Therefore topics in which the mole concept is being used to solve numerical problems in chemistry were considered viz: The mole and relative molecular masses; chemical equations and stoichiometry; gas laws and calculations involving gas volumes; solutions and solubility and electrolysis.

\section{Research Instrument}

This study made use of the Problem Solving Achievement Test in Chemistry (PSATC). This consisted of 25-item multiple choice questions constructed to serve as pretest to ascertain equivalence of ability of subjects and as post-test to determine the effect of the treatment on ability to solve numerical problems in chemistry using the mole concept. The test items were adapted from:

i. West African Examination Council (WAEC) Senior Certificate Examination;

ii. National Examination Council (NECO) Senior School Certificate Examination.

\section{Validation of Research Instruments}

The topics identified under the content area for the study above were used to prepare the table of specification for the items based on the Bloom's taxonomy of educational objectives. Fourty objective item or questions were initially drawn. Majority of the questions were on the application and higher order objectives since the study is based on students' ability to solve numerical problems in chemistry. This instrument was then given out to two experienced Chemistry teachers in the secondary schools and who are seasoned examiners of WAEC and NECO for comments on how well the items were in measuring the expected knowledge and on the correctness of the questions. Based on the comments of the assessors few questions that needed slight adjustment were corrected.

The instrument was then field-tested on a random sample of twenty five (25) students drawn from a Senior Secondary class three in Ife East Local government of Osun State. The result of the field test was used to calculate the difficulty index ( $p$ ) of the test items. Those items with $p$ value between 0.32 and 0.72 were selected. Based on this, fifteen test items were dropped and twenty five items retained. The final set of twenty - five questions was the PSATC. The reliability of the instrument was also determined using the Kuder Richardson formula 21 (K-R 21) and the reliability coefficient was found to be 0.92 .

\section{Concept Mapping Instructional Material (CMIM)}

These were designed and prepared by the researcher to teach the subjects on the mole concept and the interrelated topics. The CMIMs were in three different categories; the spider, the hierarchical and the flowchart types. These were used for the implementation of experimental group instructional activities.

\section{Data Collection}

Chemistry students in SSII in each school were used for the study. With the assistance of their Chemistry teachers the students were given the pre-test to ascertain uniformity of their entry level during the first week of the experiment. The schools were randomly assigned to the different concept-mapping strategies viz: spider, flowchart and hierarchical.

The treatment commenced a week after the administration of the pre-test. In the first week of the treatment, all the three groups were introduced to the concept mapping methods and the prepared concept maps were distributed and explained to them. The following week, teaching started in all the groups. The treatment lasted for five weeks in the three schools.

After the treatments, subjects were post-tested to determine their level of attainment/achievement in the topics covered and to find out the effect of the teaching strategies. All the scripts of the students involved in the study were marked by the researcher and the records kept for the purpose of data analysis. 


\section{Results}

In order to determine possible differences in the background knowledge of the students in their problem solving ability in Chemistry using the mole concept, the Problem Solving Achievement Test in Chemistry (PSATC) was first administered as pre-test. The data obtained was subjected to One-Way Analysis of Variance (ANOVA) and the F value was calculated. The result is presented in Table 2 below.

Table 2: Analysis of Variance of Scores of the Three Groups on the Pre-test Scores

\begin{tabular}{lccccc}
\hline $\begin{array}{l}\text { Sources of } \\
\text { variation }\end{array}$ & $\begin{array}{c}\text { Sum of } \\
\text { Squares }\end{array}$ & df & Mean Square & F & Sig. \\
\hline Between Groups & 315.585 & 2 & 157.793 & 1.189 & .307 \\
Within Groups & 20302.338 & 153 & 132.695 & & \\
Total & 20617.923 & 155 & & & \\
\hline
\end{tabular}

Since $p>0.05$, this indicated that there was no significant difference in the mean score of the three groups with respect to their performance in Chemistry as shown by their result in the pre-test.

Table 3: Mean Scores of the Three Groups in the Pre-test

\begin{tabular}{lcc}
\hline & \multicolumn{2}{c}{$\begin{array}{c}\text { Subset for alpha } \\
\text { N }\end{array}$} \\
\cline { 2 - 3 } participating & 1 & 1 \\
Flowchart Group & 37 & 30.8108 \\
Spider Group & 60 & 31.1333 \\
Heirarchical group & 59 & 33.9322 \\
Sig. & & .307 \\
\hline
\end{tabular}

Means for groups in homogeneous subsets are displayed.

\section{Hypothesis 1}

There is no significant difference in students' performance when hierarchical, flowchart and spider concept mapping methods were used to teach Chemistry.

In testing this hypothesis, the post - test scores of the students in the three groups were subjected to the Analysis of Variance (ANOVA) to determine possible differences in the problem solving ability of the students after exposure to the treatments. The results of the analysis are presented in Table 3 below.

Table 4: Analysis of Variance of Scores of the Three Groups on the Post-test

\begin{tabular}{lccccc}
\hline & Sum of & & & & \\
& Squares & df & Mean Square & F & Sig. \\
\hline Between Groups & 430.897 & 2 & 215.449 & 1.088 & .340 \\
Within Groups & 30304.692 & 153 & 198.070 & & \\
Total & 30735.590 & 155 & & & \\
\hline
\end{tabular}

From the table, It could be observed that $p>0.05$, i.e there was no significant difference in the performances of the three groups exposed to the different concept mapping strategies. Thus, the hypothesis is accepted. This implies that three concept mapping strategies used produced similar effect on the students.

However, to find out which of the three groups has a better performance though not significantly different, the means of the three groups in the pre-test were compared. This is shown in table 5. 
Table 5: Mean Scores of the Three Groups

\begin{tabular}{lrr}
\hline Participating & N & \multicolumn{2}{c}{ Subset for alpha $=.05$} \\
\cline { 2 - 4 } & \multicolumn{2}{c}{1} \\
\hline Flowchart Group & 37 & 51.5676 \\
Heirarchical Group & 59 & 53.7627 \\
Spider Group & 60 & 55.8667 \\
Sig. & & .318 \\
\hline
\end{tabular}

Means for groups in homogeneous subsets are displayed.

In the table, the mean of the group that used spider concept mapping strategies was higher than the other two groups ( $\mathrm{X}=55.8,53.8,51.6$, for Spider, Heirarchical and Flowchart concept map respectively). This indicated that spider concept mapping is more effective at imprōing students' performance in problem solving in Chemistry than hierarchical and flowchart mapping techniques.

\section{Discussion}

The findings of this study showed that the three Concept mapping strategies were effective in enhancing students' performance in Chemistry. The mean scores of the three groups in the pre-test is much lower than the mean scores of the groups in the post-test. This was due to the distinctive characteristics of the concept maps generally. One is that concept mapping is grounded in a sound cognitive learning theory, Ausubel's Assimilation Theory (Ausubel, 1968; Ausubel, Novak, \&Hanesian, 1978) which posits that knowledge can be learned most effectively by relating it to previously existing knowledge. Concept maps are viewed as a methodological tool of assimilation theory that displays fundamental elements of the theory such as subsumption, interrogative reconciliation and progressive differentiation.

Another characteristic feature of concept mapping strategy is the basic motivation for the hierarchical arrangement of concepts in concept maps which comes from Ausubel's notion of subsumption, that more general, superordinate concepts subsume more specific, detailed concepts. This theoretical notion translates to an arrangement of concepts from those that are more general toward the top of the page, with those that are more specific or detailed distributed beneath. Another defining factor of Concept maps is the use of linking phrases between concepts. Novak and Gowin (1984) state that a linking phrase should join concepts to form a meaningful learning proposition, which is a basic unit of knowledge according to the theory of meaningful learning and Ausubel's Assimilation Theory. The fundamentals of concept mapping are based on Ausubel's learning theory which in itself is based on the assumption that meaningful learning occurs when new concepts are linked to familiar concepts existing in the learner's cognitive structure and can be applied to all subject matter. The connections that concept maps facilitate learning not only allow students to draw associations amongst the main concepts being presented, but also generate greater retention, application, and understanding. (Kothe, 2009).

The result of this study is in agreement with that of Bascones and Novak (1985) in their work on the effect of concept mapping on students' problem solving in physics. The results showed that there was a positive effect for the treatment group on every test administration. Also with those of Schmid and Telaro (1990) that tested the effects of concept mapping and conventional method on improving achievement in biology. Their result indicated that the concept mapping group generally surpassed the control on the criteria test. The goal of a study by Nicoll, Francisco and Nakhleh (2001) was to investigate the value of using concept mapping in general Chemistry and, more particularly, to see if concept mapping would produce a more interconnected knowledge base in students, compared to ordinary instruction. The results showed that the concept-mapping group knew more concepts, more linking relationships, more 'useful' linking relationships and had no more erroneous linking relationships than the non-concept mapping students. This study is also in agreement with that by Chang, Sung and Chen (2002) which examined the benefits for learning of three different kinds of concept maps. The results showed that the map-correction group did better on the comprehension post-test than the map generation and control did. Other studies that agrees with this study are those by Jegede, Alaiyemola and Okebukola (1990), Pankratius (1990), Czerniak and Haney (1998), Delphonso (2003), and Omoniyi (2006), 


\section{Conclusion}

This study concludes that all the three Concept Mapping strategies are good and can enhance learning. This is because the maps clearly defined a central idea and allows one to figure out the links among the key ideas more easily and also to see all the basic information at a glance. As a result it makes recall and review more efficient. This study therefore recommends that the idea of presenting and summarizing concepts/topics in a subject by using concept map is advocated for teachers of chemistry since it is found to be effective for learning. Students should be taught how to construct concept maps on their own on various topics in chemistry and in other subjects. Concept map is a learning tool that allows the students to understand the relationship between ideas by creating a visual map of the connections. Concept map is a tool for assisting and enhancing many of the types of thinking and learning that we encountered in schools. Concept map is the most notable method of depicting the relationship between concepts today says Novak and Gowin, reported in Kothe, (2009).

\section{References}

Ausubel, D.P. (1968). Educational Psychology: A Cognitive View. New York: Holt, Rinehart and Winston Inc.

Ausubel, D.P., Novak, J.D., \& Hanesian, H. (1978). Educational Psychology: A Cognitive view. (2 ${ }^{\text {nd }}$ ed.). New York: Holt, Rinehart and Winston.

Bascones, J., \& Novak, J.D. (1985). Alternative Instructional Systems and the Development of Problem Solving Skills in Physics. European Journal of Science Education, 7(3), 253-261. http://dx.doi.org/10.1080/0140528850070304

Canas, A.J., Carff, R., Hill, G, Carvalho, M., Arguedas, M., Eskridge, T., Lott, J., \& Carvajal, R. (2005). Concept Maps: Integrating Knowledge and Information Visualization, In: Novak J.D. \& Canas, A.J. (Eds), The Origins of the concept Mapping Tool and the Continuing Evolution of the Tool.

Canas, A.J., Hill, A., Granados, J.D., \& Perez, C. C. (2003).The Network Architecture of Cmaps Tools.Technical Report ihmcCmap Tools, 93.

Chang, K., Sung, Y., \& Chen I. (2002). The Effect of Concept Mapping to Enhance Text Comprehension and Summarization. Journal of Experimental Education, 7(1), 5-23.http://dx.doi.org/10.1080/00220970209602054

Clarke, J.H. (1991). Using Visual Organizers to Focus on Thinking. Journal of Reading, 34(7), 526-534.

Coffey, J.W., Canas, A.J. Reicharzer, T, Hill, G., Suri, N. Carff, R. Mitrovich, T., \& Eberle, D. (2003). Knowledge Modelling and the Creation of El-Tech Performance Support and Training System for Electronic Technicians. Expert Systems with Applications, 25(4). http://dx.doi.org/10.1016/S0957-4174(03)00089-7

Czerniak, C.M., \& Haney, J.J. (1998). The Effect of Collaborative Concept Mapping on elementary Pre-service Teacher's Anxiety, Efficacy, and Achievement in Physical Science. Journal of Science Teacher Education, 9(4), 303-320. http://dx.doi.org/10.1023/A:1009431400397

Delphonso, B.T. (2003). Effectiveness of Concept Mapping Strategy on the Performance of Junior Secondary School Students in Learning Flowering Plants. Unpublished Masters Thesis of ObafemiAwolowo University, Ile-Ife.

Eniayeju, P.A. (2005). Enhancing Professional STM Teachers' Role in Lifelong Education: The function of Instructional Support Practices. STAN Annual Conference.

Esiobu, A.W., \& Soyibo, K. (1995). Effects of Concept and Vee Mapping Under Three Learning Modes on Students' Cognitive Achievement in Ecology and Genetics. Journal of Research in Science Teaching, 32(9), 971-995. http://dx.doi.org/10.1002/tea.3660320908

Ezeliora, B. (1999). A Comparative Analysis of the Effect of Improvised and Standard Models and Graphics on Students' Achievement and Interest in Chemistry. Journal of the Science Teachers Association of Nigeria, 34 , $1-5$.

Federal Government of Nigeria (2004). National Policy on Education. Lagos.

Ferry, B., Hedberg, J., \& Harper, B. (1998). How do Pre-service Teachers Use Concept Maps to Organize their Curriculum Content knowledge? Journal of Interactive Learning Research, 9(1), 83-84.

Jegede, O.J., Alayemola, F., \& Okebukola, P.A. (1990). The Effect of Concept Mapping on Students' Anxiety and Achievement in Biology. Journal of Research in Science Teaching, 27(10), 951-960. http://dx.doi.org/10.1002/tea.3660271004 
Kothe Denise. (2009). Meaningful Learning: A Collaborative Literature Review of Concept Mapping. Retrieved from http://www.mlrg.org/clr-conceptmapping.html

Nicoll, G, Francisco, J., \& Nakhleh, M.B. (2001). An Investigation of the Value of Using Concept Maps in General Chemistry. Journal of Chemical Education, 78(8), 1111-1117. http://dx.doi.org/10.1021/ed078p1111

Novak, J. D., \& Canas, A. J. (2008). The Theory Underlying Concept Maps and How to Construct and Use them. Technical Report IHMC Cmap Tools. Institute for Human and Machine Cognition. http://dx.doi.org/10.1017/CBO9781139173469

Novak, J.D., \& Gowin, D.B. (1984). Learning How to Learn. New York: Cambridge University Press.

Novak, J.D. (1995). Concept Mapping: A Strategy for Organizing Knowledge. In S.M. Glynn and R.A.Eduit (Eds) Learning Science in the Schools. Research Reforming Practice, pp229-245.

Omoniyi, A.O. (2006). A Study of the Relative Effectiveness of Learning Cycle and Concept Mapping Approaches for Correcting Students' Misconceptions in Chemistry. Unpublished Ph.D Thesis of Obafemi Awolowo University, Ile-Ife, Nigeria.

Salau, M.O. (2003). Constraint Against Life Coping Skills in the Implementation of the National Policy on Education at the Secondary School Level and Strategies for Redress. Journal of CON, 10(2), 465-470.

Schmid, R.F., \&Telaro, G. (1990).Concept Mapping as an Instructional Strategy for High School Biology. Journal of Educational Research, 84(2), 78-85.

Tobin, K., Tippins, D.J., \& Gallard, A.J. (1994). Research on Instructional Strategies for Teaching Science. In D. Gabel (Eds). Handbook of Research on Science Teaching and Learning. N.Y. Macmillan.

White, R., \&Gunstone, R. (1992).Probing Understanding. New York:Falmer Press.

Wikipedia. (2010). Wikipedia free Encyclopaedia. Retrieved from http://en.wikipedia.org/wiki/mole 
APPENDICES

\section{A. SPIDER CONCEPT MAPPING ON THE MOLE}

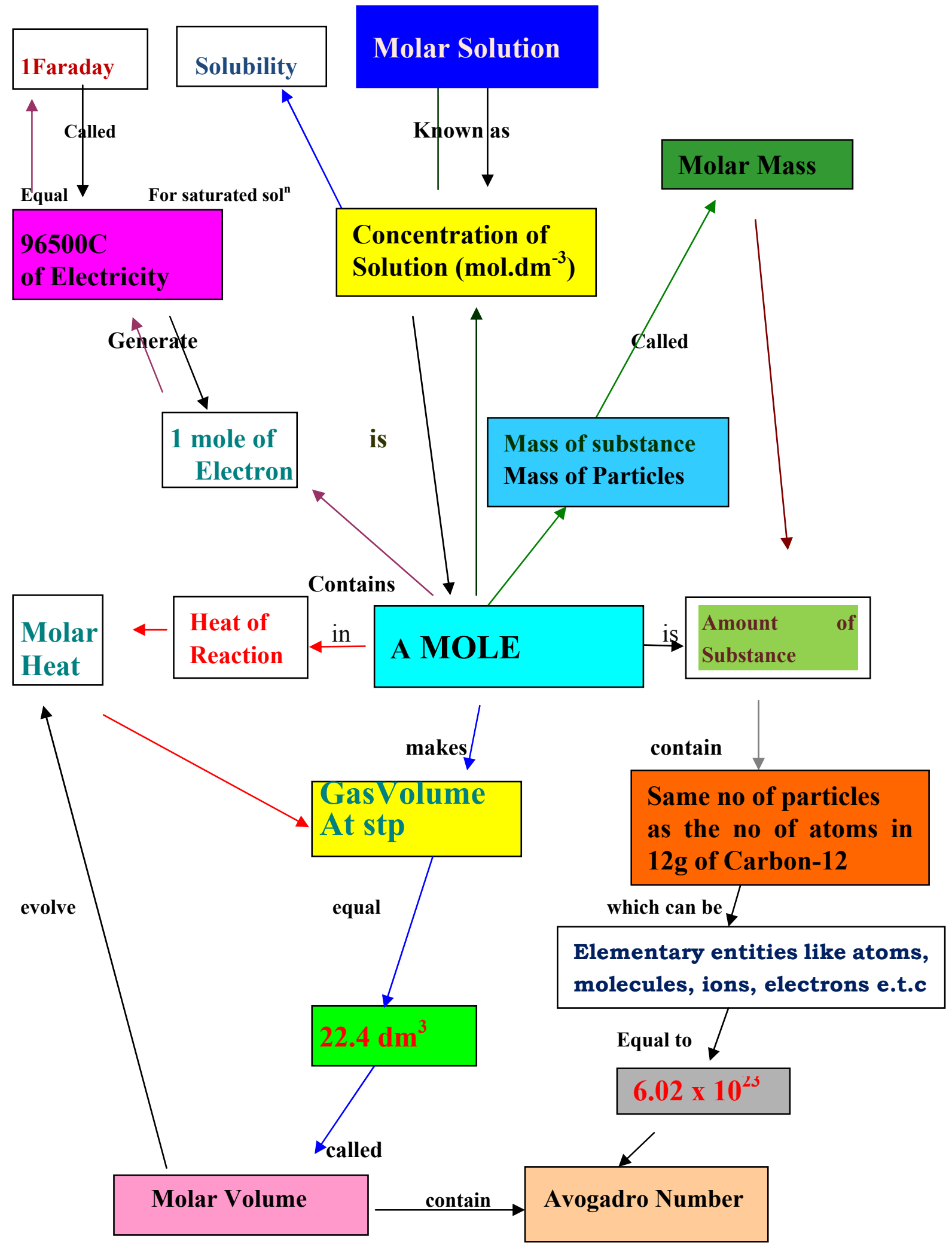




\section{B. FLOWCHART CONCEPT MAPPING}

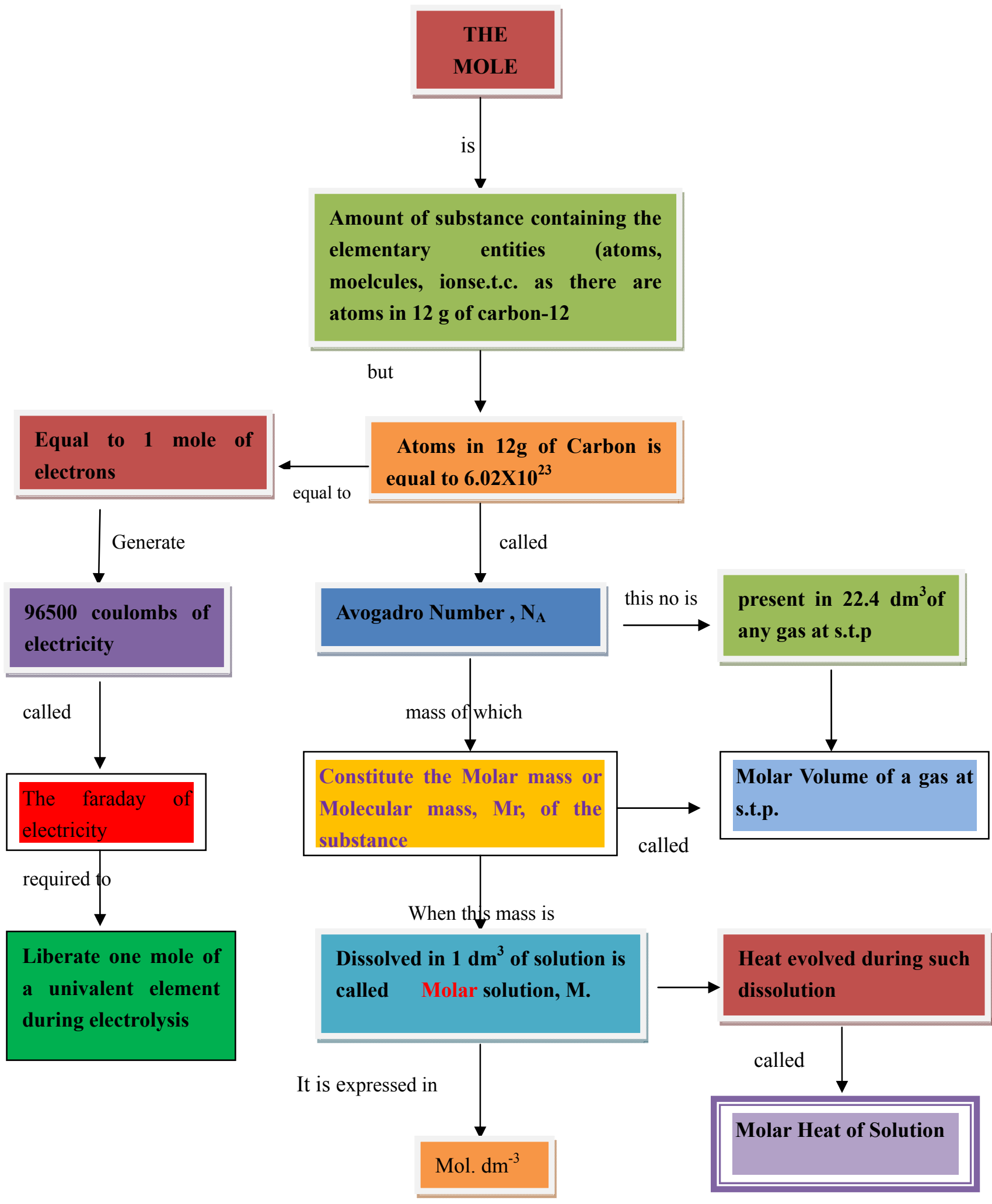




\section{Hierarchical Concept Mapping}

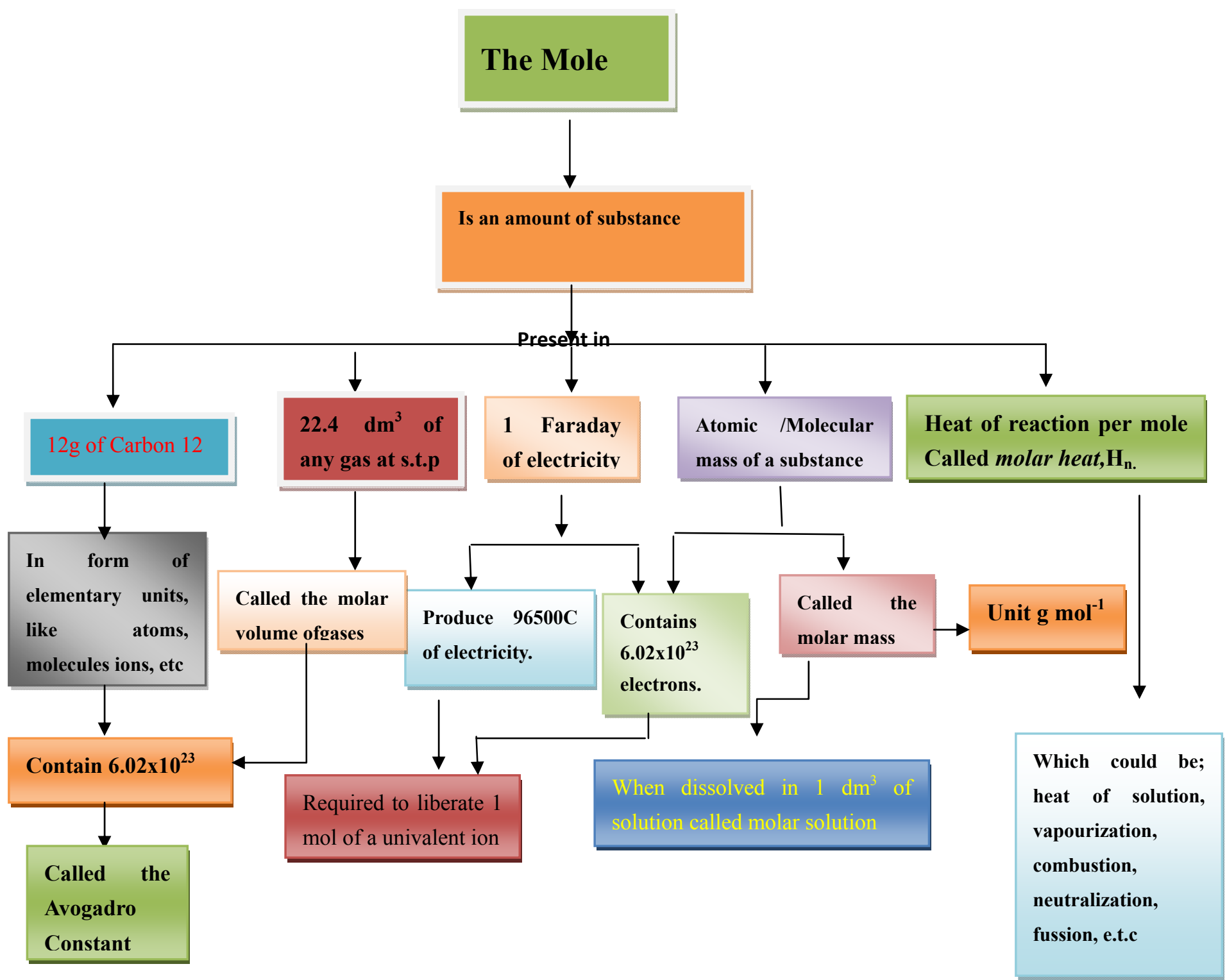

